\title{
Socio-demographic profile and psychiatric morbidities of suicide attempters: a cross-sectional observation in a tertiary care hospital of Bangladesh
}

\author{
Jotirmoy Roy, ${ }^{1}$ Md Al Fatah Al Adiluzzaman, ${ }^{2}$ Md Tanvir Hasan, ${ }^{3}$ Dibbya Duty Roy, ${ }^{4}$ MMA Shalahuddin Qusar, ${ }^{5}$ \\ Md Mohsin Ali Shah, ${ }^{6}$ SM Yasir Arafat ${ }^{7}$ \\ ${ }^{1}$ Associate Professor, Department of Psychiatry, Rangpur Medical College, Rangpur, Bangladesh; ${ }^{2}$ Registrar, Department of \\ Psychiatry, Rangpur Medical College Hospital (RMCH), Rangpur, Bangladesh; ${ }^{3}$ Intern Doctor, RMCH, Rangpur, Bangladesh; \\ ${ }^{4}$ Honorary Medical Officer, Department of Psychiatry, RMCH, Rangpur, Bangladesh; ${ }^{5}$ Professor, Department of Psychiatry, \\ Bangabandhu Sheikh Mujib Medical University (BSMMU), Dhaka, Bangladesh; ${ }^{6}$ Associate Professor, Department of Psychiatry, \\ BSMMU, Dhaka, Bangladesh; ${ }^{7}$ Resident, Department of Psychiatry, BSMMU, Dhaka, Bangladesh.
}

$\begin{array}{ll}\text { Article info } & \\ \text { Received } & : \text { 14 May } 2018 \\ \text { Accepted } & : \text { 10 Sep. } 2018 \\ \text { Number of tables } & : 03 \\ \text { Number of figures } & : 0 \\ \text { Number of refs } & : 36\end{array}$

Correspondence

Jotirmoy Roy

Mobile: +8801746639399

E-mail: drjotirmoyroy.roy@gmail.com

\begin{abstract}
Summary
Suicide is a perplexing phenomenon of taking one's own life. Reasons behind suicide attempts are also unique. Clinical characteristics of these patients have not been adequately studied from a psychosocial and psychiatric point in Bangladesh. This study was aimed to assess the sociodemographic profile and psychiatric morbidities in suicide attempters. This was a descriptive cross sectional study conducted from May 2017 to September 2017. A total of 101 patients were selected purposively who were admitted following suicide attempt in different departments of Rangpur Medical College Hospital (RMCH). Medical officers in the psychiatry department interviewed them by using a semi-structured questionnaire. Diagnosis was made according to DSM-IV. The results showed that the majority of the respondents were socio-economically deprived young persons. Most (42\%) of them were $<20$ years of age with female (53\%) preponderance. Among them $51 \%$ were unmarried, $73 \%$ were rural dwellers $37 \%$ were students and $58 \%$ attempts were impulsive. Among the respondents $63 \%$ had no prior suicidal thoughts, $56 \%$ resorted to poisoning, $49 \%$ attempted due to domestic quarrel, $65 \%$ suffered from psychiatric disorders where major depressive disorder (18\%) was found to be one of the commonest diagnosed disorders. Psychiatric disorders and their comorbidities are common in suicide attempt patients which calls for implementation of hospital guidelines for routine psychiatric and psychosocial assessments.
\end{abstract}

Bang J Psychiatry 2016;30(2):36-40

\section{Introduction}

Nearly 800,000 people die due to suicide every year, which is 1 person every 40 seconds. In 2015, suicide alone accounted for $1.4 \%$ of all deaths worldwide, making it the 17 th leading cause of death. ${ }^{1} 60 \%$ of these occur in Asia as estimated. ${ }^{1} \mathrm{~A}$ recent review of suicide in Asia demonstrates higher average suicide rates in Asia compared to high-income countries. ${ }^{2}$ Despite the fact that it is an enormous public health issue, suicide receives relatively less attention.

According to the latest data published in may 2014 by World Health Organization (WHO), suicide deaths in Bangladesh reached 10,167 or $1.40 \%$ of total deaths. The age adjusted death rate is 7.63 per 100,000 of population which ranks Bangladesh $97^{\text {th }}$ in the world. ${ }^{3}$ So it is crucial to understand the predisposing factors behind the suicide attempts among the population for preventing it. Given that most people who choose to end their lives do so for complex reasons, psychiatric problems such as depression and other mood disorders play a central role. ${ }^{4}$ Recent studies of Deliberate Self Harm (DSH) from other countries have reported high rates of psychiatric disorders as well. ${ }^{5-10}$ Study showed suicide attempt rates are 10-40 times higher than rates for completed suicides. ${ }^{11}$ The methods used for suicidal attempts are usually different, ranging from self-poisoning to hanging, self-cutting etc. This may be related to the differences in the accessibility of certain methods. In the WHO Multicentre Study, 64 per cent of males and 80 percent of females used self poisoning. ${ }^{12}$ And more than $50 \%$ of the suicide attempters made more than one attempt, and nearly $20 \%$ of the second attempts were made within 12 months after the first attempt. ${ }^{11}$ There is also socio demographic risk factors in relation to repetition, which belong to the age group of 25 to 49 years, being divorced, unemployed, and coming from low social class. ${ }^{12}$ In this study 
we aimed to assess the socio-demographic profile and psychiatric morbidities of suicide attempters through a standardized instrument and structured clinical interview.

\section{Materials and methods}

This descriptive, cross sectional study was carried out for 4 months from May 2017 to September 2017, in the Rangpur Medical College Hospital, a tertiary care hospital in Rangpur, Bangladesh. Sample was taken purposively from the patients with suicidal attempt from different departments of the hospital including Medicine, Surgery, Head-Neck and Otorhinolaryngology. A total of 101 patients were selected as the study sample. In the present study, suicide attempt was operationally defined as a non-fatal act, whether physical injury, drug overdose or poisoning, carried out in the knowledge that it was potentially harmful and in the case of drug over-dosage the amount taken was excessive. ${ }^{13}$ Informed written consent was obtained from all patients. The interview was conducted once the patient was considered fit for a psychosocial assessment using a semi-structured questionnaire and clinical interviews. Medical officers attached to the psychiatry unit trained in interview techniques assessed these patients. Diagnosis was made by consultant psychiatrist according to DSM-IV TR. ${ }^{13}$ Data was entered and analyzed using Statistical Package for Social Sciences (SPSS) version 24 and results were expressed as proportions and percentages.

\section{Results}

The results showed that, majority $(42 \%)$ of the respondents were below 20 years old. Female constituted $53 \%$, half (51\%) of the sample was unmarried, $73 \%$ lived in rural area, $39 \%$ were students, majority (95\%) belonged to Islamic faith, 37\% completed higher secondary school, $43 \%$ had a monthly family income of 10001-20000 BDT and most (60\%) lived within a nuclear family (Table 1). Fifty eight percent attempts were impulsive, $26 \%$ planned before attempting and 16\% were unable to decide. No prior suicidal thoughts were present among $63 \%$ of respondents and $8.3 \%$ had no history of previous attempts. However, $14 \%$ of the respondents reported previous suicide attempts for more than once (Table 2). In the study, $56 \%$ resorted to poisoning as the mode of suicide attempt. $24 \%$ tried to hang themselves, $15 \%$ overdosed with drug and only $5 \%$ used self-cutting as the method. Among the study sample 6 patients used more than two methods to suicide. On narrative analysis, reasons that had the most influences in attempting suicide were Domestic Quarrel (49\%), Relationship issues (9\%), medical illness (5\%), Failure in examination (3\%) and other reasons accounted for $13 \%$ (Table 2).
Table 1: Distribution of suicide attempters according to socio-demographic variables $(n=101)$

\begin{tabular}{|c|c|}
\hline Characteristics & Frequency (\%) \\
\hline \multicolumn{2}{|l|}{ Age (in years) } \\
\hline $11-20$ & $42(42 \%)$ \\
\hline $21-30$ & $26(26 \%)$ \\
\hline $31-40$ & $23(23 \%)$ \\
\hline 41 and above & $10(9 \%)$ \\
\hline \multicolumn{2}{|l|}{ Gender } \\
\hline Male & $48(47 \%)$ \\
\hline Female & $53(53 \%)$ \\
\hline \multicolumn{2}{|l|}{ Marital status } \\
\hline Married & $30(30 \%)$ \\
\hline Unmarried & $52(51 \%)$ \\
\hline Divorced/separated/widowed & $19(19 \%)$ \\
\hline \multicolumn{2}{|l|}{ Habitat } \\
\hline Urban & $27(27 \%)$ \\
\hline Rural & $74(73 \%)$ \\
\hline \multicolumn{2}{|l|}{ Educational status } \\
\hline Primary & $34(34 \%)$ \\
\hline Secondary & $25(25 \%)$ \\
\hline Higher secondary & $38(37 \%)$ \\
\hline Graduate & $4(4 \%)$ \\
\hline \multicolumn{2}{|l|}{ Post graduate } \\
\hline \multicolumn{2}{|l|}{ Occupation } \\
\hline Student & $39(39 \%)$ \\
\hline Service holder & $7(7 \%)$ \\
\hline Business & $20(20 \%)$ \\
\hline Cultivator & $16(16 \%)$ \\
\hline Housewife & $10(10 \%)$ \\
\hline Unemployed & $9(8 \%)$ \\
\hline \multicolumn{2}{|l|}{ Monthly family income (BDT) } \\
\hline$<10000$ & $30(29 \%)$ \\
\hline $10001-20000$ & $43(43 \%)$ \\
\hline $20001-30000$ & $20(20 \%)$ \\
\hline 30001 and above & $8(8 \%)$ \\
\hline \multicolumn{2}{|l|}{ Religion } \\
\hline Islam & $96(95 \%)$ \\
\hline Hindu & $4(4 \%)$ \\
\hline Buddhist & $1(1 \%)$ \\
\hline \multicolumn{2}{|l|}{ Family type } \\
\hline Nuclear & $61(60 \%)$ \\
\hline Joint & $40(40 \%)$ \\
\hline
\end{tabular}


Table 2: Suicide attempt data $(n=101)$

\begin{tabular}{|c|c|}
\hline Characteristics & Frequency (\%) \\
\hline \multicolumn{2}{|l|}{ Nature of attempt } \\
\hline Impulsive & $59(58 \%)$ \\
\hline Planned & $26(26 \%)$ \\
\hline Unable to decide & $16(16 \%)$ \\
\hline \multicolumn{2}{|l|}{ Prior suicidal thoughts } \\
\hline Present & $37(37 \%)$ \\
\hline Absent & $64(63 \%)$ \\
\hline \multicolumn{2}{|c|}{ History of previous attempts } \\
\hline No & $83(82 \%)$ \\
\hline Yes (once) & $4(4 \%)$ \\
\hline More than once & $14(14 \%)$ \\
\hline \multicolumn{2}{|l|}{ Mode of attempt } \\
\hline Drug Overdose & $15(15 \%)$ \\
\hline Poisoning & $57(56 \%)$ \\
\hline Hanging & $24(24 \%)$ \\
\hline Jump from height & $0(\%)$ \\
\hline Jump in front of vehicle & $0(\%)$ \\
\hline Self-cutting & $5(5 \%)$ \\
\hline Drowning & $0(\%)$ \\
\hline Gunshot & $0(\%)$ \\
\hline \multicolumn{2}{|l|}{ Reasons for attempt } \\
\hline Financial problems & $9(9 \%)$ \\
\hline Relationship issues & $21(21 \%)$ \\
\hline Domestic quarrel & $49(49 \%)$ \\
\hline Medical illness & $5(5 \%)$ \\
\hline Failure in examination & $3(3 \%)$ \\
\hline Others & $14(13 \%)$ \\
\hline
\end{tabular}

Two percent of the patients had a family history of psychiatric illness and $5 \%$ had history of attempted/complete suicide in the family. Substance abuse was reported in families of $4 \%$ of patients, $9 \%$ had previous history of psychiatric illness, $7 \%$ admitted about substance abuse in their lifetime. Evaluation of psychiatric disorders revealed $4 \%$ suffering from substance related disorders, $7 \%$ suffering from personality disorder, $12 \%$ from conversion disorder, $18 \%$ from major depressive disorder and $36 \%$ from other condition that may be a focus of clinical attention (Table 3).
Table 3: Distribution of respondents according to the types of psychiatric morbidities $(n=101)$

\begin{tabular}{lc}
\hline Psychiatric diagnosis & Frequency (\%) \\
\hline Personality disorder & $7(7 \%)$ \\
Schizophrenia & $5(5 \%)$ \\
Other psychotic disorders & $7(7 \%)$ \\
Major depressive disorder & $18(18 \%)$ \\
Bipolar mood disorder & $6(6 \%)$ \\
Delusional disorder & $7(7 \%)$ \\
Conversion disorder & $12(12 \%)$ \\
Substance related disorder & $4(4 \%)$ \\
Other condition that may be a focus & $32(31 \%)$ \\
of clinical attention & \\
Adjustment disorder & $2(2 \%)$ \\
More than one morbidity & $1(1 \%)$ \\
\hline
\end{tabular}

\section{Discussion}

Suicide was one of the priority conditions in the WHO Mental Health Gap Action Programme (mhGAP) launched in 2008. ${ }^{14}$ However, globally, the availability and quality of data on suicide and suicide attempts was poor. As the largest continent in the world, Asia accounted for about $60 \%$ of world suicides, and there had been a lack of systematic exploration of suicide methods in Asian countries. ${ }^{15}$ This was indifferent in the perspective of Bangladesh as well. There was no surveillance for suicide and nationwide study on suicide was yet to be conducted. ${ }^{16}$ In our present study, we gathered the data on socio-demographic and suicide attempt profile, and psychiatric morbidities of the subjects with history of attempted suicide presenting to a tertiary care hospital. The study group consisted of one hundred and one subjects. The data obtained in our sample was consistent with few earlier studies. ${ }^{16,17}$ The under 20 age group had the majority of suicide attempts in our study with $42 \%$ possession and this was well in co-ordinance with the study of Feroz et $\mathrm{al}^{17}$ and Shah et al. ${ }^{18}$ In many Indian studies individuals below 30 years of age were found to be more vulnerable for attempting suicide. ${ }^{19-23}$ Female accounting $53 \%$ had the highest presence in our study and in the review article of S.M. Yasir Arafat comprising 9 original articles, 3 review articles and 1 other type (thesis) also stated the same. ${ }^{16}$ The male-female ratio is slightly inclined towards the females was possible due to passive gender role, early marriage, lack of economic freedom, low literacy and such cultural factors predominant in the Asian countries. ${ }^{16,24,25}$

The rural people attempted suicide most in the current study $(73 \%)$ and this was similar to other studies in perspective of Bangladesh. ${ }^{16,17,18,25}$ Unmarried subjects were also found to be slightly more than married $(51 \%)$ which could be explained 
by the study from Denmark which reported cohabiting or single marital status was a significant risk factor for suicide. ${ }^{26}$ Being separated or divorced was noted to be significantly associated with a suicidal act in another study. ${ }^{27}$ And to add, Patel et $a^{28}$ found that the male-to-female ratio was smaller in Asia than in other parts of the world which can be demonstrated from the data we got. For occupation and educational literacy, students $(39 \%)$ were the highest attempters and overall most subjects showed a good literacy of up to higher secondary level (37\%). As opposed to this, unemployment was found to be significantly associated with suicide in previous literature from India and the West. ${ }^{18,26,27,29,30}$ Financial status belonging mostly to lowermiddle class $(43 \%)$ in the study with $60 \%$ of nuclear families, was also in relation to that of previous study. ${ }^{16,18}$

Fifty six percent of our cases belonged to poisoning as the form of suicide attempt and the finding correlated with other global findings. ${ }^{16,31,32}$ In one of the other studies, hanging was found to be the commonest method of suicide, ${ }^{16,18}$ but the $2^{\text {nd }}$ commonest $(24 \%$ ) in our study. This could be explained by the agriculture based society Bangladesh has and since majority of our subjects belonged to the rural community. Sato et al, found a relation between occupation (agriculture) and method used for attempt. ${ }^{31}$ Easy availability of compounds within the home or premises rendered them the first preference for attempting suicide. ${ }^{32,33}$ An association was observed between method availability and method specific suicide rates. ${ }^{33}$ Impulsivity was commonest among our study group (58\%), which resembles the report of Van Spijker et al. ${ }^{34}$ They also reported that, $46.7 \%$ were planned attempters in their study but only $26 \%$ were found in our study. Only $37 \%$ of our study subjects had prior suicidal thoughts which coincided with the statistical figure (about $23 \%$ ) of the study conducted by Ponnudurai et al. ${ }^{20}$ Domestic quarrel (49\%) and relationship issues (21\%) accounted the most behind suicide attempts among the study group and this confirmed the trend of other studies. ${ }^{16,18,25}$

While assessing psychiatric disorders we found $65 \%$ of the suicide attempters suffered from a psychiatric disorder. Major depressive disorder (18\%) and conversion disorder (12\%) were found to be the most common diagnosed disorders. However $35 \%$ of the subjects who initially considered for psychiatric evaluation didn't show any clinical morbidity and was grouped under condition that may be a focus of clinical attention. And while only $1 \%$ had more than one psychiatric disorders, such co-morbidities was also reported. ${ }^{35,36}$

\section{Conclusion}

Despite the global concern, suicide is still a neglected and under attended public health problem in our country. The time demanded step of establishing national suicide surveillance is depended on scientific studies. Taken together all the findings, our results lead us to the conclusion that the variables enhancing the risk of suicide among the vulnerable groups if identified and the predictive items associated with suicidal risks are enlisted, it would effectively help in early detection and prevention of suicide attempts.

\section{References}

1. World Health Organization. Suicide data. Geneva: World Health Organization; 2016.

2. Chen YY, Wu KCC, Yousuf S, Yip PS. Suicide in Asia: opportunities and challenges. Epidemiol Rev 2012;34(1):129-44.

3. Suicide in Bangladesh [Internet]. World Life Expectancy. Available from: http://www.worldlifeexpectancy.com/bangladesh-suicide

4. World Health Organization. World report on violence and health. Geneva: World Health Organization; 2014.

5. Ennis J, Barnes RA, Kennedy S. Depression in self-harm patients. Br J Psychiatry 1989;154:41-7.

6. Beautrais AL, Joyce PR, Mulder RT, Fergusson DM, Deavoll BJ, Nightingale SK. Prevalence and co morbidity of mental disorders in persons making serious suicide attempt: a case control study. Am J Psychiatry 1996;153:1009-14.

7. Souminen K, Henriksson M, Soukas J, Isometsa E, Ostamo A, Lonnqvist J. Mental Disorders and co morbidity in attempted suicide. Acta Psychiatr Scand 1996;94:234-40.

8. Ferreira de Castro E, Cunha M, Pimenta F. Parasuicide and mental disorders. Acta Psychiatr Scand 1998;97:25-31.

9. Haw C, Hawton K, Houston K, Townsend E. Psychiatric and personality disorders in deliberate self-harm patients. $\mathrm{Br} \mathrm{J}$ Psychiatry 2001;178:48-54.

10. Hawton K, Houston K, Haw C, Townsend E, Harris L. Comorbidity of Axis-I and Axis-II Disorder in patients who Attempted Suicide. Am J Psychiatry 2003;160:1494-1500.

11. Schmidtke A, Bille-Brahe U, DeLeo D. Attempted suicide in Europe: rates, trends and sociodemographic characteristics of suicide attempters during the period 1989-1992. Results of the WHO/EURO Multicentre Study on Parasuicide. Acta Psychiatr Scand, 1996;93(5):327-38.

12. Harrison P, Cowen P, Burns T, editors. Shorter Oxford Textbook of Psychiatry. $6^{\text {th }}$ ed. New York: Oxford University Press; 2000.

13. American Psychiatric Association. Diagnostic and statistical manual of mental disorders. $4^{\text {th }}$ ed (text revision). Washington DC: American Psychiatric Association; 2000.

14. World Health Organization. Suicide Prevention Day. Geneva: World Health Organization; 2017.

15. Wu KC, Chen YY, Yip PS. Suicide methods in Asia: Implications in suicide prevention. Int $\mathrm{J}$ Environ Res Public Health 2012;9:1135-58.

16. Arafat SMY. Suicide in Bangladesh: a Mini Review. J Behav Heal. 2017;6(1):66-9.

17. Feroz AHM, Islam SN, Reza S, Rahman AM, Sen J, Mowla M, et al. A Community Survey on the Prevalence of Suicidal Attempts and Deaths in a Selected Rural Area of Bangladesh. J Med 2012;13(1):3-9. 
18. Shah MMA, Ahmed S, Arafat SMY. Demography and Risk Factors of Suicide in Bangladesh: A Six-Month Paper Content Analysis. Psychiatry J 2017;2017:5.

19. Chandrasekaran R, Gnanaseelan J, Sahai A, Swaminathan RP, Perme B. Psychiatric and personality disorders in survivors following their first suicide attempt. Indian J Psychiatry 2003;45(2):45-8.

20. Ponnudurai R, Jeyakar J, Saraswathy M. Attempted suicides in Madras. Indian J Psychiatry 1986;28(1):59-62.

21. Narang RL, Mishra BP, Nitesh M. Attempted suicide in Ludhiana. Indian J Psychiatry 2000;42(1):83-7.

22. Kumar PNS. Age and gender related analysis of psychosocial factors in attempted suicide. Indian J Psychiatry 1998;40(4): $338-45$.

23. Khan MM. Suicide prevention and developing countries. J R Soc Med 2005;98:459-63.

24. Jordans MJ, Kaufman A, Brenman NF, Adhikari RP, Luitel NP, Tol WA, et al. Suicide in South Asia: a scoping review. BMC Psychiatry 2014;14:358.

25. RezaAS, Feroz AHM, Islam SN, Karim MN, Rabbani MG, Alam MS, et al. Risk Factors of Suicide and Para Suicide in Rural Bangladesh. J Med 2014;14(2):123-9.

26. Qin P, Agerbo E, Mortensen PB. Suicide Risk in Relation to Socioeconomic, Demographic, Psychiatric, and Familial Factors: A National Register-Based Study of All Suicides in Denmark, 1981-1997. Am J Psychiatry 2003;160(4):765-72.

27. Blackmore ER, Munce S, Weller I, Zagorski B, Stansfeld SA, Stewart DE, et al. Psychosocial and clinical correlates of suicidal acts: Results from a national population survey. Br J Psychiatry 2008;192(4):279-84.

28. Patel V, Ramasundarahettige C, Vijayakumar L, Thakur JS, Gajalakshmi V, Gururaj G, et al., Suicide mortality in India: A nationally representative survey. Lancet 2012;379(9834):2343-51.

29. Srivastava MK, Sahoo RN, Ghotekar LH, Dutta S, Danabalan M, Dutta TK, et al. Risk factors associated with Attempted Suicide: A case control study. Indian J Psychiatry 2004;46(1):33-8.

30. Kar N. Profile of risk factors associated with suicide attempts: A Study from Orissa, India. Indian J Psychiatry 2010;52(1):48-56.

31. Sato T, Takeichi M, Hara T. Suicide attempts by agriculture chemicals. Indian J Psychiatry 1993;35(4):209-10.

32. Bose A, Sejbaek CS, Suganthy P, Raghava V, Alex R, Muliyil J, et al. Self-harm and self poisoning in southern India: choice of poisoning agents and treatment. Trop Med Int Health 2009;14(7):761-5.

33. Marzuk PM, Leon AC, Tardiff K, Morgan EB, Stajic M, Mann JJ. The effect of access to lethal methods of injury on suicide rates. Arch Gen Psychiatry 1992;49(6):451-8.

34. Van Spijker BAJ, Graafsma T, Dullaart, Kerkhof HIA. Impulsive but Fatal Self-Poisoning with Pesticides Among South Asians in Nickerie, Suriname: An Exploratory Autopsy Study. Crisis 2009;30(2):102-5.

35. Das PP, Grover S, Avasthi A, Chakrabarti S, Malhotra S, Kumar S. Intentional self-harm seen in psychiatric referrals in tertiary care hospital. Indian J Psychiatry 2008;50(3):187-91.

36. Haw C, Hawton K, Houston K, Townsend E. Psychiatric and personality disorders in deliberate self-harm patients. $\mathrm{Br} \mathrm{J}$ Psychiatry 2001;178:48-54. 